\title{
Como Classificar o Paciente em Fleboestética
}

\author{
Miyake K. ${ }^{1}$ \\ ${ }^{1}$ São Paulo - SP. \\ E-mail:kasuomiyake@gmail.com
}

Miyake, K. 2013. Como Classificar o Paciente em Fleboestética, p.35. In: Bastos, Francisco Reis. Anais do V Simpósio Internacional de Flebologia [Blucher Medical Proceedings n.1 v.1]. São Paulo: Blucher, 2014

http://dx.doi.org/10.5151/medpro-flebo-SIF_16
Desde 1980, Dr Hiroshi Miyake já descrevia em suas aulas a importância da palpação da pele e boa iluminação para que as veias nutrícias fossem "pescadas" e as telangiectasias resistentes ao tratamento eliminadas "pela raiz". Dr Hiroshi também frisava a importância do exame da safena. Naquela época não havia ultrassonografia e ele sempre considerou a flebografia um exame invasivo, com risco de alergia e flebite e portanto não indicava o exame para pacientes com problemas estéticos. Dizia que mesmo se a paciente fosse assintomática, sem veia safena palpável mas tivesse uma "tufo de telangiectasias" sobre a safena... a safena precisava ser retirada para que a lesão venosa fosse eliminada. Os anos se passaram e hoje em dia temos a disposição aparelhos de ultrassonografia de alta definição e portáteis, transiluminadores de pele e também a Realidade Aumentada (RA). Aparelhos de RA filmam a pele e projetam sobre a pele uma imagem das veias que estão abaixo da pele. Tudo isso é feito em uma fração de segundos e nos permite ter a sensação que estamos vendo as veias que estão a profundidades de até $5 \mathrm{~mm}$.

Conhecimentos adquiridos do Dr Hiroshi e o uso de tais tecnologia no dia-a-dia desde 2005 nos fez desenvolver o "Superficial Venous Score 9-1" uma classificação específica para o tratamento de fleboestética visto que as classificações existentes como o CEAP não visam determinar se há ou não a presença de veias nutrícias; o que consideramos fundamental para o sucesso no tratamento das lesões venosas estéticas de perna.

Nessa aula discutiremos os diferentes tipos de classificação assim como as opções terapêuticas para cada uma delas.

Palavras-chave: fleboestética, varizes, IVC, tratamento de varizes. 